\title{
PENINGKATAN MUTU SERAT DAUR ULANG KOTAK KARTON GELOMBANG BEKAS MENGGUNAKAN CMC
}

\author{
Sonny Kurnia Wirawan ${ }^{1}$, Nina Elyani, Ike Rostika \\ Balai Besar Pulp dan Kertas \\ Jl. Raya Dayeuh Kolot 132 Bandung 40258 \\ ${ }^{1}$ sonny_bbpk@yahoo.co.id \\ Diterima : 16 Februari 2015, Revisi akhir : 30 April 2015, Disetujui terbit : 15 Mei 2015
}

QUALITY IMPROVEMENT OF OLD CORRUGATED CARDBOARD USING CMC

\begin{abstract}
The use of recycled fibers derived from old corrugated cardboard (OCC) potential for enhanced strength properties through the addition of carboxy methylcellulose (CMC). Research carried out on local OCC with variation of time reaction, temperture, and the dosage of of $\mathrm{CMC}$ and $\mathrm{CaCl}_{2}$. Handsheet laboratory was made, and then analyzed the strength properties include tensile index, tensile energy absorption (TEA) index, bursting index and folding endurance, as well as coarseness and kink. The results show the optimum condition is achieved on the conditions of the reaction time of 20 minutes, the reaction suhue $25^{\circ} \mathrm{C}$, the concentration of $\mathrm{CMC} 0.75 \%$ and concentration $\mathrm{CaCl}_{2} 0.5 \%$. Strength properties improvement was achieved at $3.07 \%$ tensile index, folding endurance $43.75 \%$ and bursting strength $36.81 \%$.
\end{abstract}

Keywords: CMC, OCC, strength properties

\begin{abstract}
ABSTRAK
Sifat kekuatan serat daur ulang yang berasal dari kotak karton gelombang $(\mathrm{KKG})$ bekas berpotensi untuk ditingkatkan melalui penambahan karboksi metil selulosa (CMC). Penelitian dilakukan terhadap KKG bekas lokal dengan variasi waktu, suhu, dan dosis penambahan $\mathrm{CMC}$ dan $\mathrm{CaCl}_{2}$. Lembaran kertas dibuat secara laboratorium, kemudian dianalisis sifat kekuatan meliputi indek tarik, indek tensile energy absorption (TEA), indek retak, dan ketahanan lipat, serta analisis coarseness dan kink. Hasil penelitian menunjukan kondisi optimum dicapai pada waktu reaksi 20 menit, suhu reaksi $25^{\circ} \mathrm{C}$, konsentrasi CMC 0,75\% dan konsentrasi $\mathrm{CaCl}_{2}$ 0,5\%. Peningkatan kekuatan yang dihasilkan adalah indeks tarik 3,07\%, ketahanan lipat $43,75 \%$ dan indeks retak $36,81 \%$.
\end{abstract}

Kata kunci: CMC, KKG bekas, sifat kekuatan

\section{PENDAHULUAN}

Salah satu kendala terbesar dalam penggunaan serat daur ulang seperti kotak karton gelombang (KKG) bekas adalah penurunan sifat kekuatan serat, selain itu terjadi juga fenomena hornifikasi yang menyebabkan penurunan kemampuan serat untuk mengembang (swelling), sehingga fleksibilitas serat akan menurun. Serat menjadi lebih rapuh dan kaku, sehingga mengurangi ikatan antar serat (Kontturi dkk., 2005).

Penurunan sifat kekuatan kertas daur ulang secara langsung diakibatkan oleh penurunan kemampuan ikatan antar serat, yang dapat diakibatkan karena menurunnya daya swelling dan elastisitas serat. Pada proses hornifikasi sebagian besar dari lignin dan hemiselulosa dihilangkan selama proses pemasakan kimia, sehingga pori-pori yang terbentuk antara lapisan mikrofibril selulosa kristal, sebagai struktur pipih. Pada saat serat terendam air di proses pembuatan kertas, serat akan mengembang dan pori-pori akan terisi air, kemudian ketika serat dikeringkan, mikrofibril akan saling berikatan dan apabila serat kembali mengalami pembasahan (pada serat daur ulang) maka hasilnya tidak reversibel sehingga pembentukan kembali ikatan antar serat akan berkurang (Kontturi dkk., 2005). 
Karboksimetilasi merupakan suatu metode untuk meningkatkan gugus hidroksil dan swelling pada serat, yang berdampak pada peningkatan kekuatan kertas ( Fors, 2000). Proses karboksimetilasi serat menunjukan akan terjadinya peningkatan kekuatan ikatan spesifik antar serat, akan tetapi proses ini memiliki kekurangan bahwa pada serat yang telah mengalami proses swelling akan cenderung lebih sulit untuk proses dewatering. (Duker dan Lindstrom, 2008)

Salah satu cara untuk meningkatkan kembali gugus hidroksil dan daya swelling serat adalah dengan karboksimetilasi (Nelson dan Kalkipsakis, 1964). Penelitian sebelumnya mengenai peningkatan mutu serat menggunakan karboksi metil selulosa (CMC) telah dilakukan, akan tetapi metode yang digunakan pada penelitian sebelumnya masih menggunakan sumber serat panjang yang berasal dari pulp kayujarum seperti Needle Bleached Kraft Pulp (NBKP) dan dilakukan pada suhu tinggi (Duker dan Lindstrom, 2008; Blomstedt dan Minna, 2007; Liimatainen dkk., 2009). Selain itu penelitian sebelumnya (Wirawan dkk.2012 menggunakan sumber bahan baku serat kraft putih kayudaun (LBKP) dan serat hasil deinking (DIP) pada suhu $50-55^{\circ} \mathrm{C}$. Hal ini akan menghambat penerapan pada skala industri, adanya kenaikan suhu akan meningkatkan biaya produksi kertas, sehingga dikembangkan metode reaksi CMC dengan serat menggunakan suhu lebih rendah.
Tujuan penelitian ini adalah untuk meningkatkan kualitas serat KKG bekas, dengan penggunaan CMC. Serta mencari kondisi optimum proses modifikasi serat dengan penambahan CMC.

\section{BAHAN DAN METODE}

Penelitian dilakukan terhadap KKG bekas lokal dengan kadar air 5,36\% dan derajat giling $490 \mathrm{~mL}$ CSF (Canadian Standard Freeness). CMC yang digunakan adalah grade teknis dengan kadar air 14,44\% dan derajat subtitusi (DS) 0,4076 serta $\mathrm{CaCl}_{2}$ menggunakan kemurnian tingkat pro analis (p.a).

\section{Pembuatan Lembaran dari Pulp KKG Bekas}

KKG bekas dipotong dengan ukuran kurang lebih $1 \mathrm{~cm}^{2}$, kemudian dilakukan penggilingan hingga mencapai derajat giling 300 CSF, dan ditambahkan aquades hingga mencapai konsistensi $2,5 \%$, kemudian dilakukan variasi penambahan $\mathrm{CaCl}_{2}$ dan $\mathrm{CMC}$ serta kondisi reaksi seperti pada Tabel 1. Kemudian dibuat lembaran kertas secara laboratorium dengan gramatur $70 \mathrm{~g} / \mathrm{m}^{2}$.

\section{Analisis Sifat Fisik Lembaran dan Analisis Kink Serta Coarseness}

Lembaran contoh uji dikondisikan terlebih dahulu sesuai SNI 14 - 01402 - 1999 tentang

Tabel 1. Variasi Pembuatan Lembaran

\begin{tabular}{|c|c|c|c|c|c|}
\hline Kode & Waktu reaksi (menit) & Suhu $\left({ }^{\circ} \mathrm{C}\right)$ & Kons. CMC (\%) & Kons. $\mathrm{CaCl}_{2}(\%)$ & Keterangan \\
\hline 0 & - & 23 & - & - & Blanko \\
\hline 1 & 10 & & & & \\
\hline 2 & 20 & 60 & 0.75 & 1.5 & Variasi waktu reaksi \\
\hline 3 & 30 & & & & \\
\hline 4 & & 25 & & & \\
\hline 5 & 20 & 40 & 0.75 & 1.5 & Variasi suhu reaksi \\
\hline 6 & & 60 & & & \\
\hline 7 & & & 0.5 & 1.5 & \\
\hline 8 & 20 & 25 & 0.75 & & Variasi dosis CMC \\
\hline 9 & & & 1 & & \\
\hline 14 & & & & 0.5 & \\
\hline 15 & 20 & 25 & 0.75 & 1 & Variasi dosis $\mathrm{CaCl}_{2}$ \\
\hline 16 & & & & 1.5 & \\
\hline
\end{tabular}


kondisi ruang dan pengkondisian lembaran pulp, kertas dan karton untuk pengujian, penyimpanan contoh pada suhu $23 \pm 1^{\circ} \mathrm{C}$ dan kelembaban udara (RH) $50 \pm 2 \%$, kemudian dilakukan analisis ketahanan tarik menggunakan metode SNI ISO 1924-2:1994, ketahanan retak sesuai dengan ISO 2758:2011, dan ketahanan lipat menggunakan metode SNI 0491:2009. Kemudian untuk mendapatkan nilai indeks tarik $(\mathrm{Nm} / \mathrm{g})$ diperoleh dengan cara membagi ketahanan tarik $(\mathrm{N} / \mathrm{m})$ dibagi gramatur $\left(\mathrm{g} / \mathrm{m}^{2}\right)$, indeks TEA $(\mathrm{J} / \mathrm{g})$ diperoleh dengan cara membagi TEA $(\mathrm{J} / \mathrm{m})$ dengan gramatur $\left(\mathrm{g} / \mathrm{m}^{2}\right)$ dan untuk indeks retak $(\mathrm{kN} / \mathrm{g})$ diperoleh dengan cara membagi ketahanan retak $(\mathrm{kPa})$ dengan gramatur $\left(\mathrm{g} / \mathrm{m}^{2}\right)$. Untuk analisis kink dan coarseness, dilakukan menggunakan alat Fiber tester buatan Lorentzen \& Wettre.

\section{HASIL DAN PEMBAHASAN}

\section{Pengaruh Waktu Reaksi Terhadap Kekuatan Lembaran}

Waktu reaksi memegang peranan penting dalam modifikasi serat secara toposelektif menggunakan polimer $\mathrm{CMC}$, hal ini dikarenakan perlu adanya waktu untuk menempelnya polimer CMC terhadap permukaan serat. Penelitian sebelumnya telah dilakukan modifikasi serat dengan CMC dengan waktu yang relatif lama yaitu 60-120 menit (Duker dan LindstrÖm, 2008; Blomstedt \& Minna, 2007). Pada penelitian ini dicari waktu yang lebih pendek dalam rangka untuk meningkatkan efisiensi di pabrik kertas.

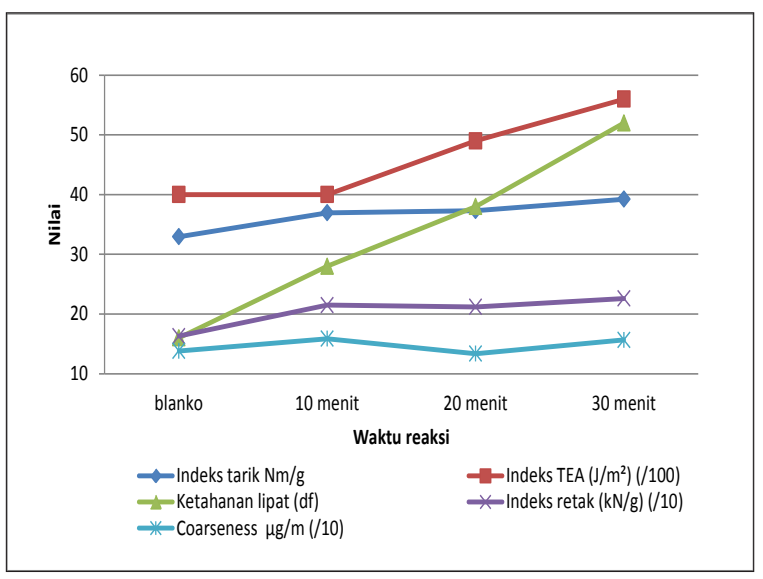

Gambar 1. Pengaruh Waktu Reaksi Terhadap Kekuatan Lembaran

Dari Gambar 1 terlihat bahwa dengan peningkatan waktu reaksi kecenderungan kekuatan lembaran cenderung meningkat, akan tetapi pada industri kertas waktu reaksi atau waktu tinggal sangat mempengaruhi produktivitas, sehingga dengan pertimbangan ini dipilih waktu reaksi 20 menit dengan alasan pada waktu reaksi 20 menit sudah terjadi peningkatan kekuatan lembaran yang signifikan, yaitu pada parameter indeks tarik 13,23\%, indeks TEA 22\%, ketahanan Lipat 225\%, dan indeks retak $38.7 \%$. Sedangkan pada waktu reaksi yang lebih lama peningkatan kekuatan lembaran sudah cenderung tetap atau sama.

\section{Pengaruh Suhu Terhadap Kekuatan Lembaran}

Pada penelitian sebelumnya proses toposelektif CMC terhadap serat perlu pemanasan pada suhu reaksi $120^{\circ} \mathrm{C}$ (Duker E dan Lindström, 2008) dan $50^{\circ}-55^{\circ} \mathrm{C}$ (Wirawan, dkk.2012). Gambar 2 menunjukan bahwa dengan peningkatan suhu $25^{\circ}-60^{\circ} \mathrm{C}$, kekuatan lembaran yang dihasilkan cenderung relatif sama, sehingga kondisi penambahan CMC dipilih pada suhu kamar $\left(25^{\circ} \mathrm{C}\right)$ untuk pertimbangan efisiensi apabila diterapkan di industri kertas.

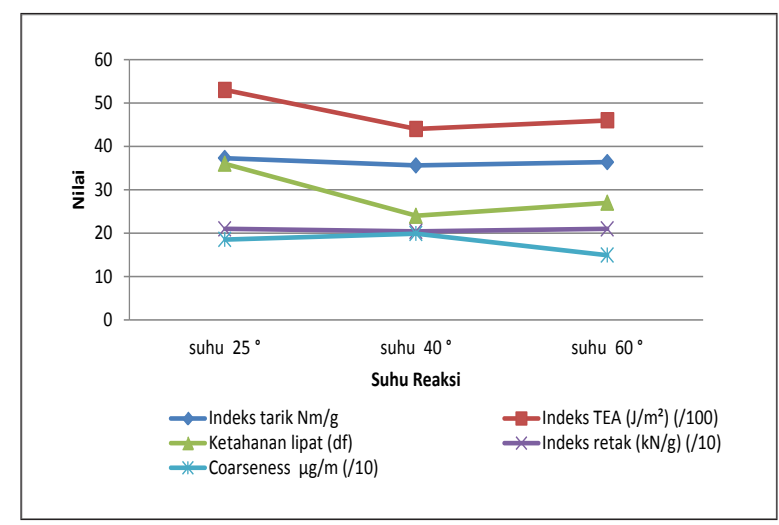

Gambar 2. Pengaruh Suhu terhadap Kekuatan Lembaran

\section{Pengaruh Dosis CMC terhadap Kekuatan Lembaran}

Kink merupakan salah satu sifat yang dihasilkan dari deformasi serat yang mempengaruhi sifat kekuatan serat. Peningkatan jumlah kink akan menyebabkan penurunan ketahanan tarik zero span, jumlah kink dapat dikurangi melalui "pelurusan" serat seperti dengan valley beating (Zeng Xiling, dkk., 2012). Pada Gambar 3 terlihat penambahan dosis CMC akan menyebabkan penurunan jumlah kink/mm dan meningkatkan 
ketahanan tarik lembaran. Penambahan CMC akan berpengaruh secara signifikan terhadap jumlah kink serat Hal ini kemungkinan dikarenakan adanya dampak penambahan CMC terhadap pelurusan serat karena adanya gaya tolak-menolak antar gugus karboksil pada permukaan serat. Serat yang lurus akan meningkatkan distribusi tegangan efektif pada kertas sehingga dapat meningkatkan ketahanan tarik lembaran (Duker dan LindstrÖm, 2008).

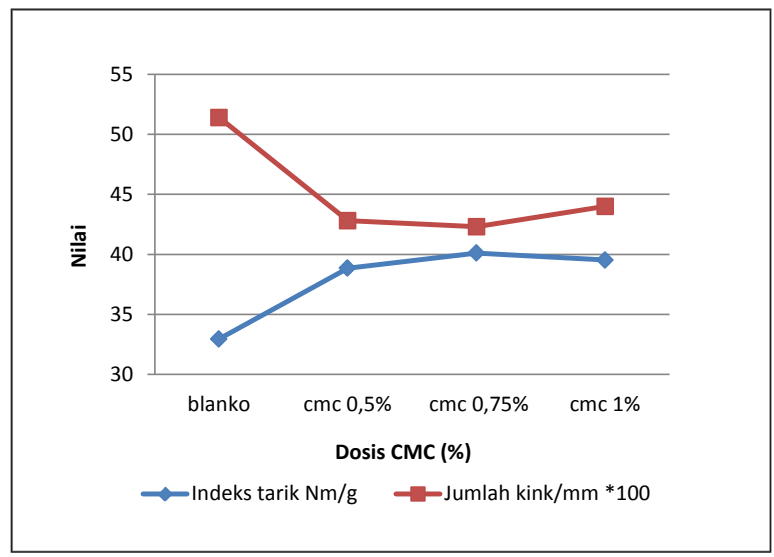

Gambar 3. Pengaruh Dosis CMC terhadap Jumlah Kink dan Indeks Tarik

Pada industri kertas umumnya untuk meningkatkan kekuatan lembaran dilakukan penambahan serat panjang. Hal tersebut dikarenakan yang mempengaruhi kekuatan lembaran, diantaranya adalah panjang serat yang dapat mempengaruhi nilai ketahanan tarik. Jumlah dan ikatan antar serat merupakan parameter yang penting untuk mengoptimasi sifat kekuatan tarik (Herbert Holik (Ed.). 2006.)

Pada Gambar 4 terlihat bahwa penambahan dosis CMC dapat meningkatkan kekuatan lembaran, hal ini sesuai dengan penelitian sebelumnya, yang menyatakan bahwa penambahan CMC akan meningkatkan jumlah ikatan antar serat yang akhirnya meningkatkan kekuatan lembaran.Selain itu penambahan CMC dapat meningkatkan formasi dari mikrofibril yang banyak mengandung air pada permukaan serat (Mittika-Eklund,dkk, 1999). Dari gambar 4 terlihat bahwa dosis CMC yang optimum adalah pada penambahan CMC $0.75 \%$. Peningkatan kekuatan yang diperoleh pada penambahan CMC $0.75 \%$, yaitu indeks tarik $21.70 \%$, TEA $32,5 \%$, ketahanan lipat 60\%, dan ketahanan retak $294 \%$.

Kekasaran serat atau fiber coarseness didefinisikan sebagai berat serat per panjang serat.
Coarseness tergantung pada diameter, ketebalan dinding sel, densitas dinding sel dan perlintangan arah serat. Nilai coarseness sangat berpengaruh terhadap struktur kertas. Nilai coarseness yang tinggi menunjukan dinding serat yang tebal, sehingga memiliki kekakuan serat yang tinggi dan tidak mudah untuk roboh. Makin tinggi nilai coarseness serat, maka makin tinggi kekuatan lembaran (Ramezani dan Mousa, 2004). Dari Gambar 5 terlihat bahwa dengan penambahan dosis CMC maka nilai indeks retak dan tarik juga meningkat dan nilai coarseness serat juga meningkat.Hal ini diduga karena penambahan CMC dapat meningkatkan daya swelling serat sehingga serat menjadi lebih tebal.

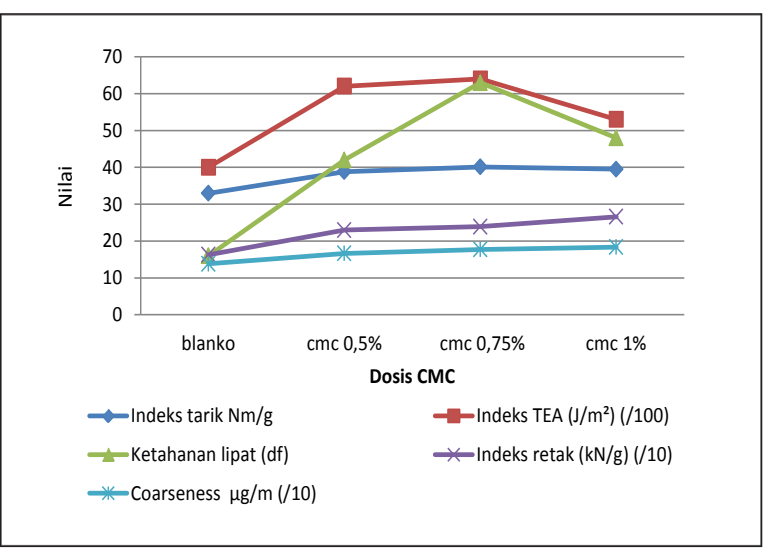

Gambar 4. Pengaruh Dosis CMC terhadap Kekuatan Lembaran

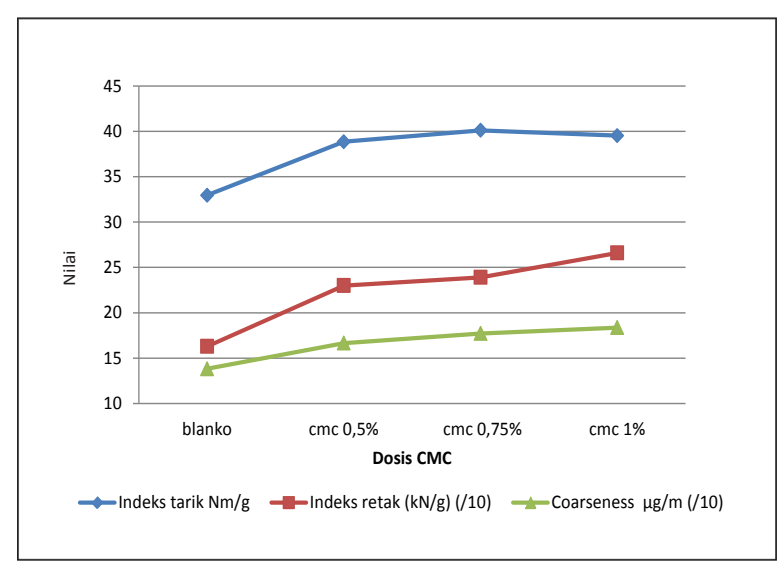

Gambar 5. Pengaruh dosis CMC terhadap Coarseness dan Kekuatan Lembaran

\section{Pengaruh Dosis $\mathrm{CaCl}_{2}$ terhadap Kekuatan Lembaran}

Daya serap CMC dipengaruhi oleh DS dan kehadiran elektrolit. Tanpa keberadaan elektrolit, 
CMC hanya sedikit terserap oleh serat yang bersifat anionik. Hal ini dapat dikarenakan adanya gaya tolak-menolak dari muatan yang sama yang terkandung pada CMC dan serat (Wirawan, dkk.2012). Hal ini juga mendukung penelitian sebelumnya bahwa keberadaan elektrolit akan mengurangi daya tolak-menolak antara muatan negatif $\mathrm{CMC}$ dan serat, yang menyebabkan peningkatan adsorbsi CMC. (Mittika-Eklund, dkk., 1999; Ramezani dan Nazhad, 2004).

Dari Gambar 6 dapat diketahui bahwa dosis optimum untuk penambahan elektolit $\mathrm{CaCl}_{2}$ adalah pada dosis $0,5 \%$, karena setelah peningkatan dosis $\mathrm{CaCl}_{2}$ yang lebih tinggi tidak menunjukkan perbedaan kekuatan yang signifikan. Peningkatan kekuatan yang diperoleh pada penambahan $\mathrm{CaCl}_{2} 0.5 \%$, yaitu indeks tarik $3,0 \%$, ketahanan lipat $43,75 \%$, dan indeks retak $36,81 \%$ sedangkan TEA tidak menunjukkan perbedaan.

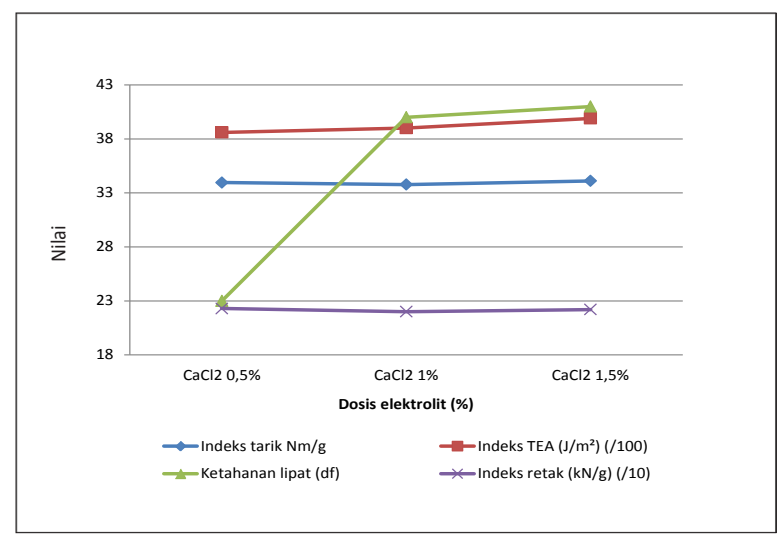

Gambar 6. Pengaruh $\mathrm{CaCl}_{2}$ terhadap Kekuatan Lembaran

\section{KESIMPULAN}

Proses penambahan $\mathrm{CMC}$ dan $\mathrm{CaCl}_{2}$ terhadap serat $\mathrm{KKG}$ bekas memberikan hasil positif terhadap kekuatan lembaran. Kondisi terbaik proses modifikasi serat yaitu pada kondisi waktu reaksi 20 menit, suhu reaksi $25^{\circ} \mathrm{C}$, konsentrasi $\mathrm{CMC} 0.75 \%$ dan konsentrasi $\mathrm{CaCl}_{2}$ $0.5 \%$, dengan peningkatan kekuatan indeks tarik $3,07 \%$, ketahanan lipat $43,75 \%$, dan indeks retak $36,81 \%$.

\section{UCAPAN TERIMA KASIH}

Pada kesempatan ini penulis mengucapkan terima kasih sebanyak-banyaknya pada Ibu Ike
Rostika, rekan-rekan teknisi Litkayasa Dadang SA., Maman S., Cucu, Enung FM., yang telah membantu dalam penelitian ini.

\section{DAFTAR PUSTAKA}

Blomstedt, Minna. 2007. Modification of Cellulosic Fibers By Carboxymethyl Cellulosed - Effects On Fiber And Sheet Properties. Laboratory Of Forest Products Chemistry, Reports. Helsinki. Espoo.

Duker E., LindstrÖm, T. 2008. On the Mechanism Behind the ability of CMC to enhance Paper Strength. Nordic Pulp and Paper Research journal Vol. 23 no.1.hal. 57-64

Fors, C. (2000) The effect of fibre charge on web consolidation in papermaking. Licentiate thesis, Royal Institute of Technology, Department of Pulp and Paper Chemistry and Technology, Stockholm, Sweden, 78 p.

Herbert Holik (Ed.). 2006. Handbook of Paper and Board. Wiley VCH Verlag $\mathrm{GmbH} \&$ Co. KGaA. Weinheim

Kontturi, Eero J.. - Eindhoven. 2005. chemistry of cellulose : from natural fibres to model surfaces Proefschrif. Technische Universiteit Eindhoven,. Espoo. Finland

Liimatainen Henrikki, Haavisto Sanna, Haapala Antti, Niinimaki Jouko. 2009. Influence of Adsorbed and Dissolves CMC on Fibre Suspension Dispersing, Dewaterability, and Fines Retention. Bioresources 4 (1): 321-340

Mittika-Eklund, M., Halttunen, M., Melander M., Ruutunen, K., Vuorinen, T. (1999). "Fiber engineering, " $10^{\text {th }}$ International Symposium on Wood and Pulping Chemistry, June 7-10, Yokohama, 432-439.

Nelson, P.F., Kalkipsakis, C.G. (1964) The Behavior of Salts of Carboxymetylated Eucalypt Kraft Pulp. TAPPI 47(3): 170-176

Ramezani, O., Nazhad M. Mousa, 2004, The effect of coarseness on the paper formation. African pulp and paper week 2004. http:// tappsa.co.za/archive2/APPW_2004/ Title2004/the_effect__of_c.didownload tanggal 03-09-2013.

Wirawan, Sonny K.,Elyani, N., Rismijana, J., 2012.Modifikasi permukaan serat LBKP dan hasil deinking dengan karboksimetil selulosa.Jurnal selulosa. Vol.2 No.2. Desember 2012, hal:71-80

Zeng, X., Retulainen, E., Heinemann, S., Fu, S., 2012. Fibre deformations induced by different mechanical treatments and their effect on zero-span strength. Nordic Pulp and Paper Research Journal Vol 27 No.2 
Lurnal Selulosa, Vol. 5, No. 1, Juni 2015 : 33 - 38 